\title{
The effect of different substrates on the growth of six cultivated mushroom species and composition of macro and trace elements in their fruiting bodies
}

\author{
Marek Siwulski ${ }^{1}$ Piotr Rzymski · Anna Budka ${ }^{3}$. Pavel Kalač ${ }^{4}$ Sylwia Budzyńska ${ }^{5}$. Luiza Dawidowicz ${ }^{1}$. \\ Edmund Hajduk $^{6} \cdot$ Lidia Kozak $^{7} \cdot$ Joanna Budzulak ${ }^{2} \cdot$ Krzysztof Sobieralski $^{1} \cdot$ Przemysław Niedzielski $^{7}$
}

Received: 28 June 2018 / Revised: 22 September 2018 / Accepted: 29 September 2018 / Published online: 19 October 2018

(c) The Author(s) 2018

\begin{abstract}
There is an ongoing interest in the production of mushrooms as food, and with their consumption on the rise, there is a need to establish different safety measures. In the present study, six mushroom species (Agrocybe cylindracea, Clitocybe maxima, Flammulina velutipes, Ganoderma lucidum, Lentinula edodes and Pleurotus eryngii) were cultivated on two commonly used substrates (A—based on alder and beech sawdust; B — based on oak sawdust and flax shives). The aims were to determine their growth and the accumulation of 70 elements in their fruiting bodies, 33 of which were detected in all analysed samples and were used for statistical evaluation. Cultivation of C. maxima, G. lucidum and L. edodes resulted in higher yield and mineral content when substrate A was used, cultivation of $A$. cylindracea and $F$. velutipes yielded better results on substrate B, P. eryngii cultivation outcomes were similar for both substrates. L. edodes was found to have a high affinity to accumulate $\mathrm{Cd}, C$. maxima can bioconcentrate $\mathrm{Al}$ and $\mathrm{Ni}$, Ganoderma lucidum- $\mathrm{Pb}$, while $F$. velutipes $-\mathrm{Hg}$. The study indicated that the chemical composition of substrates could affect both the yield and the level of various toxic and nutritional elements.
\end{abstract}

Keywords Food safety $\cdot$ Cultivated mushrooms $\cdot$ Cultivation substrate $\cdot$ Accumulation $\cdot$ Chemical elements

\section{Introduction}

Mushrooms are an important food product, which is particularly valued as a delicacy in Asia and Central-Eastern Europe for their taste, nutritional value and biological activity [1-6]. Apart from traditional collection of wild mushrooms, there is a growing interest in cultivated forms [7, 8]. Mushroom production and import is facing a dynamic development in various world regions. In 2016, their global production was over 10 million metric tons, including almost 8 million tons in China [9].

Almost all available lignocellulosic substances, including various types of waste from agriculture, horticulture, forestry, the textile and wood industry can be used for growing mushrooms $[10,11]$. Various species have been cultivated on sawdust obtained from different tree species with a variety of additive ingredients such as wheat bran, corn meal, cereal grains and other organic materials. Some substrates also contain mineral additives, mostly in the form of gypsum and/or chalk. It is well established that the use of substrates composed of mixtures of various materials is more beneficial 
for the production than the use of homogeneous substrates due to the enriched nutritional environment [12-14].

Mushrooms are known to uptake and accumulate various chemical elements [5, 15-18]. However, the efficiency of this process can be species dependent and can be influenced by bioavailability of elements $[4,19]$. The enrichment of mushrooms with essential minerals may significantly increase the nutritional and pharmaceutical value of the final product and broaden its application. Recently, the concept of mushrooms enriched in various elements such as selenium $(\mathrm{Se})$, lithium $(\mathrm{Li})$, zinc $(\mathrm{Zn})$ or copper $(\mathrm{Cu})$ for use as functional foods has been developed [67 16, 20-24].

Various studies have shown that mushrooms can also contain toxic metals and metalloids (e.g. As). Consumption of wild mushrooms collected from polluted areas or mushrooms cultivated on contaminated substrates increases the risk of exposure to toxic elements (e.g. Ag, $\mathrm{As}, \mathrm{Cd}, \mathrm{Hg}, \mathrm{Ni}$ and $\mathrm{Pb}$ ) $[4,15,19,25]$. Some elements are accumulated commensurately high concentration of an element in the environment is reflected in its high accumulation in the fruiting body. Other elements, e.g. $\mathrm{Cd}$ and $\mathrm{Hg}$, accumulated in disproportionately high content in mushrooms is caused by the intensive absorption from the environment but not by a high abundance of the element in the environment hyperaccumulation $[18,26]$. The substrates used for mushroom cultivation have been shown to vary in their chemical composition, including content of trace elements. Therefore, it can be expected that the quality of substrate may significantly affect the growth and chemical composition of cultivated mushrooms [27, 28]. This highlights the need to perform multi-elemental investigations of cultivated mushrooms and specifically substrates which are used for mushroom cultivations.

Therefore, the aim of the present study was to compare the growth of six commercially cultivated mushroom species (Agrocybe cylindracea, Clitocybe maxima, Flammulina velutipes, Ganoderma lucidum, Lentinula edodes and Pleurotus eryngii) on two commercial substrates and the accumulation of detectable chemical elements in their fruiting bodies.

\section{Materials and methods}

\section{Experimental material}

Agrocybe cylindracea (AE11), Clitocybe maxima (CM02), Flammulina velutipes (F04), Ganoderma lucidum (GL01), Lentinula edodes (SH37) and Pleurotus eryngii (B167) strains were obtained from the mushroom collection of Poznań University of Life Science (Department of Vegetable Crops). The primary mycelium on agar medium and spawn on wheat grain were prepared according to the methods described earlier (Mleczek et al. 2018). All of these mushrooms are considered as edible, except G. lucidum which has a bitter taste due to specific triterpenoid content although fruiting bodies of this species are commercially used to produce various food products such as food supplements [29].

\section{Cultivation design}

Two types of substrates (marked as A and B) were used in the experiments. Characteristics of element contents are given in Table 1. Substrate A was prepared from a mixture of alder and beech sawdust $(1: 1 \mathrm{v} / \mathrm{v})$ which was additionally supplemented with wheat bran in the amount of $25 \%$, cornmeal $12 \%$, millet $10 \%$, chalk $2 \%$, gypsum $0.97 \%, \mathrm{KH}_{2} \mathrm{PO}_{4}$ $0.02 \%$ and $\mathrm{MgSO}_{4} 0.01 \%$. The doses of the supplements in both the substrates are expressed as a percentage of the weight of the basic mixtures.

Substrate B was prepared from a mixture of oak sawdust and flax shives $(1: 1 \mathrm{v} / \mathrm{v})$ which was additionally supplemented with ground rye in the amount of $20 \%$, sorghum $10 \%$, defatted soy flour $10 \%$, oat bran $8 \%$, gypsum $1.97 \%$, $\mathrm{KH}_{2} \mathrm{PO}_{4} 0.02 \%$ and $\mathrm{MgSO}_{4} 0.01 \%$. The substrates were blended with a POLYMIX PX-SR 90 D stirrer (KINEMATICA AG, Littau-Luzern, Switzerland) and moistened with distilled water to a moisture content of $60 \%$.

The substrates were then placed in polypropylene bottles of $0.85 \mathrm{dm}^{3}$ volume. Each bottle was filled with $450 \mathrm{~g}$ of the substrate and closed with a cover with a polypropylene filter (class F-9, Filtropol, Poland). The bottles were used for cultivation of $A$. cylindracea, $C$. maxima, F. velutipes and $P$. eryngii,. In the case of G. lucidum and L. edodes polypropylene foil sacs with a PP filter (class H-11, Filtropol, Poland) were used. Each sac for G. lucidum contained the same quantity of the substrate as the above-described bottles but for L. edodes $1 \mathrm{~kg}$ of substrate was used. Five experimental replicates were conducted for each cultivation combination.

The substrates were sterilized at a temperature of $121{ }^{\circ} \mathrm{C}$ for 1 hour and then were cooled down to a temperature of $25^{\circ} \mathrm{C}$. The substrates in the bottles were afterwards inoculated with $10 \mathrm{~g}$ of spawn (on wheat grain), the substrates in the sacs with $10 \mathrm{~g}$ of spawn for G. lucidum and $20 \mathrm{~g}$ for L. edodes.

The incubation was conducted at a temperature of $25{ }^{\circ} \mathrm{C}$ and $80-85 \%$ air relative humidity until the substrate became completely covered with mycelium. Next, the bottles with removed covers and bags with the top part of the foil cut off were placed in the cultivation chamber. For C. maxima, a 1-cm layer of vermiculite (moisture of $22 \%$ ) was placed on the top of the substrate. In L. edodes, the incubation was carried out for 90 days and then the foil was completely removed from the substrate blocks. For fructification, air relative humidity was maintained at $85-90 \%$ and temperature at $12 \pm 1{ }^{\circ} \mathrm{C}$ for $F$. velutipes, $15 \pm 1{ }^{\circ} \mathrm{C}$ for L. edodes and P. eryngii, $18 \pm 1{ }^{\circ} \mathrm{C}$ for $A$. cylindracea, and $25 \pm 1^{\circ} \mathrm{C}$ for $\mathrm{G}$. lucidum and $28 \pm 1{ }^{\circ} \mathrm{C}$ 
Table 1 Concentration $\left[\mathrm{mg} \mathrm{kg}^{-1} \mathrm{dm}\right.$ ] of elements in substrates (A and B) used in the experiment

\begin{tabular}{|c|c|c|}
\hline Element & Substrate A & Substrate B \\
\hline $\mathrm{Ca}$ & $12300^{\mathrm{a}} \pm 342$ & $10400^{\mathrm{b}} \pm 759$ \\
\hline $\mathrm{K}$ & $3170^{\mathrm{a}} \pm 128$ & $3070^{a} \pm 212$ \\
\hline $\mathrm{Mg}$ & $992^{\mathrm{a}} \pm 55.7$ & $705^{\mathrm{b}} \pm 30.2$ \\
\hline $\mathrm{Na}$ & $169^{\mathrm{a}} \pm 21.0$ & $165^{\mathrm{a}} \pm 7.77$ \\
\hline $\mathrm{P}$ & $6470^{a} \pm 194$ & $5260^{\mathrm{b}} \pm 171$ \\
\hline $\mathrm{Al}$ & $5.34^{\mathrm{b}} \pm 0.47$ & $13.2^{\mathrm{a}} \pm 2.27$ \\
\hline B & $<$ LOD & $0.68 \pm 0.12$ \\
\hline $\mathrm{Ba}$ & $174^{\mathrm{a}} \pm 18.1$ & $155^{\mathrm{a}} \pm 15.3$ \\
\hline $\mathrm{Be}$ & $0.10^{\mathrm{a}} \pm 0.03$ & $0.09^{\mathrm{a}} \pm 0.02$ \\
\hline $\mathrm{Cd}$ & $0.56^{\mathrm{a}} \pm 0.10$ & $0.55^{\mathrm{a}} \pm 0.05$ \\
\hline $\mathrm{Cr}$ & $18.3^{\mathrm{a}} \pm 0.97$ & $16.6^{\mathrm{a}} \pm 3.05$ \\
\hline $\mathrm{Cu}$ & $4.6^{\mathrm{a}} \pm 0.85$ & $3.97^{a} \pm 0.29$ \\
\hline $\mathrm{Eu}$ & $0.06^{\mathrm{a}} \pm 0.01$ & $0.01^{\mathrm{b}} \pm 0.00$ \\
\hline $\mathrm{Fe}$ & $216^{\mathrm{b}} \pm 16.0$ & $313^{\mathrm{a}} \pm 25.6$ \\
\hline $\mathrm{Hg}$ & $0.57^{b} \pm 0.11$ & $0.95^{\mathrm{a}} \pm 0.12$ \\
\hline $\mathrm{Ir}$ & $1.03^{\mathrm{a}} \pm 0.06$ & $0.57^{\mathrm{b}} \pm 0.07$ \\
\hline $\mathrm{La}$ & $0.19^{\mathrm{a}} \pm 0.03$ & $0.18^{\mathrm{a}} \pm 0.02$ \\
\hline $\mathrm{Li}$ & $0.05^{\mathrm{b}} \pm 0.01$ & $0.16^{\mathrm{a}} \pm 0.01$ \\
\hline $\mathrm{Mn}$ & $104^{\mathrm{a}} \pm 7.03$ & $62.2^{\mathrm{b}} \pm 3.96$ \\
\hline $\mathrm{Nd}$ & $0.63^{b} \pm 0.28$ & $1.08^{\mathrm{a}} \pm 0.07$ \\
\hline $\mathrm{Ni}$ & $0.41^{b} \pm 0.05$ & $1.54^{\mathrm{a}} \pm 0.26$ \\
\hline $\mathrm{Pb}$ & $5.20^{\mathrm{a}} \pm 0.31$ & $4.31^{\mathrm{b}} \pm 0.47$ \\
\hline $\operatorname{Pr}$ & $1.11^{\mathrm{a}} \pm 0.12$ & $0.66^{\mathrm{b}} \pm 0.20$ \\
\hline $\mathrm{Pt}$ & $2.50^{\mathrm{a}} \pm 0.24$ & $2.29^{a} \pm 0.18$ \\
\hline $\mathrm{Rb}$ & $39.8^{\mathrm{a}} \pm 3.10$ & $42.8^{a} \pm 2.49$ \\
\hline $\mathrm{Ru}$ & $0.41^{\mathrm{b}} \pm 0.04$ & $0.66^{\mathrm{a}} \pm 0.09$ \\
\hline $\mathrm{Sb}$ & $69.7^{\mathrm{a}} \pm 6.94$ & $68.1^{\mathrm{a}} \pm 4.81$ \\
\hline $\mathrm{Si}$ & $72.0^{\mathrm{b}} \pm 5.66$ & $104^{\mathrm{a}} \pm 5.32$ \\
\hline Sn & $9.54^{\mathrm{a}} \pm 1.29$ & $0.68^{\mathrm{b}} \pm 0.03$ \\
\hline $\mathrm{Sr}$ & $20.3^{b} \pm 3.79$ & $48.7^{\mathrm{a}} \pm 2.83$ \\
\hline $\mathrm{Tl}$ & $2.86^{\mathrm{a}} \pm 0.56$ & $3.21^{\mathrm{a}} \pm 0.38$ \\
\hline $\mathrm{Tm}$ & $0.17^{\mathrm{a}} \pm 0.08$ & $0.20^{\mathrm{a}} \pm 0.07$ \\
\hline $\mathrm{Zn}$ & $29.3^{\mathrm{a}} \pm 2.19$ & $22.6^{\mathrm{a}} \pm 4.22$ \\
\hline
\end{tabular}

Identical superscripts $(a, b)$ denote no significant $(p<0.05)$ difference between mean values in rows

$L O D$ limit of detection

for C. maxima. The cultivation was additionally lighted with fluorescent light of $500 \mathrm{~lx}$ intensity $12 \mathrm{~h}$ a day. The growth chamber was aerated in such a way as to maintain $\mathrm{CO}_{2}$ concentration below $1000 \mathrm{ppm}$. Fruiting bodies were harvested successively as they matured. Yield included whole fruiting bodies.

\section{Procedure}

Samples of complete fruiting bodies ( $200 \mathrm{~g}$ ) from each cultivation were preliminarily dried at $40 \pm 1{ }^{\circ} \mathrm{C}$ for $12 \mathrm{~h}$ and next at $80 \pm 1{ }^{\circ} \mathrm{C}$ to constant weight in an electric oven (SLW 53 STD, Pol-Eko, Wodzisław Śląski, Poland) and ground in a laboratory Cutting Boll Mill PM 200 (Retsch GmbH, Haan, Germany). Accurately weighed $0.50 \pm 0.01 \mathrm{~g}$ of a dry powdered mushroom sample was digested by concentrated nitric acid (Merck, Germany) in closed Teflon containers in the microwave sample preparation system Mars 5 Xpress. After the digestion, the samples were filtered through paper filters and diluted with water to a final volume of $15.0 \mathrm{~mL}$.

\section{Instruments}

The inductively coupled plasma optical emission spectrometry technique [Agilent 5100 ICP-OES (Agilent, USA)] was used for the determination of 70 elements. A simultaneous axial and radial view of plasma was allowed by the synchronous vertical dual view (SVDV). The common conditions were used for multi-elemental determination: radio frequency (RF) power $1.2 \mathrm{~kW}$, nebulizer gas flow $0.7 \mathrm{~L}$ $\mathrm{min}^{-1}$, auxiliary gas flow $1.0 \mathrm{~L} \mathrm{~min}{ }^{-1}$, plasma gas flow 12.0 $\mathrm{L} \mathrm{min}^{-1}$, viewing height for radial plasma observation $8 \mathrm{~mm}$, detector CCD (charge coupled device) temperature $-40{ }^{\circ} \mathrm{C}$, and signal accusation time $5 \mathrm{~s}$ for three replicates. For sample digestion, the microwave sample preparation system Mars 5 (CEM, Matthews, USA) was applied.

\section{Analytical method validation}

The detection limits were determined on the order of magnitude of $0.0 \mathrm{X} \mathrm{mg} \mathrm{kg}^{-1}$ dry matter (d.m.) or better for all elements determined (as three-sigma criteria). The uncertainty for total analytical procedure (including sample preparation) was below the level of $20 \%$. The traceability was checked using reference materials CRM S-1-loess soil, CRM NCSDC $(73,349)$ - bush branches and leaves, CRM 2709soil, CRM 405-estuarine sediments, CRM 667-estuarine sediments and the recovery (80-120\%) was acceptable for most of the elements determined. The recovery for uncertified elements was defined in the standard addition method.

\section{Statistical analysis}

Statistical analysis was performed using Statistica 10 software (StatSoft) and the Agricole package (R) for statistical computing and graphics. Statistical analysis was performed to show the occurrence of significant differences between element content in mushroom species growing on two different substrates. To determine similarities or differences in the content of all studied elements jointly between particular mushroom species growing on the two substrates, multivariate analysis (MANOVA) was calculated according to the two-way factorial design with the Hotelling-Lawley procedure. The next two-way analysis of variance (ANOVA) was 
performed to determine the significant differences between content of particular elements in all studied mushroom species growing on the two substrates and Tukey's HSD (honestly significant difference) test. To determine the significant differences between content of particular elements in the analysed mushroom species separately, and also to compare the content of these elements in both the substrates, the $T$ test was performed. For graphical presentation of relations between the content of elements and particular mushroom species, a principal component analysis (PCA) was performed.

Moreover, to show which fruit bodies of the analysed mushroom species $\left(S_{\mathrm{A}}\right.$ and $\left.S_{\mathrm{B}}\right)$ are characterized by the highest content of (a) all 33 elements jointly, (b) 5 major minerals ( $\mathrm{Na}, \mathrm{K}, \mathrm{Ca}, \mathrm{Mg}$, and $\mathrm{P}$ ), and (c) the rest of the trace 28 elements jointly, the Friedman repeated measures analysis of variance by ranks was used (Friedman 1937). Additionally, to characterize which fruit bodies of mushroom species growing on substrates A and B are the richest in all the studied elements, the rank sum was determined, separately for 33, 5 and 28 elements.

\section{Results}

\section{Morphology and biomass of fruiting bodies}

For all studied species, no differences in morphology of fruit bodies were recorded regardless of the substrate used for cultivation (Fig. 1). Their colour and shape were typical with no negative symptoms on the fungus gill. The growth of $A$. cylindracea, $C$. maxima and $P$. eryngii on the substrates A and B did not differ, while $F$. velutipes, $G$. lucidum and $L$. edodes revealed a significantly higher yield when grown on substrate A (Fig. 2). In general, the highest biomass of the collected fruit bodies was characteristic for P. eryngii growing on substrates B and A (294 \pm 9 and $252 \pm 29 \mathrm{~g}$ per bottle, respectively), while the lowest was recorded for $C$. maxima growing on substrates A and B $(104 \pm 4$ and $91 \pm 13$ g per bottle, respectively). The mean $( \pm \mathrm{SD})$ biomass calculated for the six mushroom species growing on substrates $A$ and B was $196 \pm 38$ and $178 \pm 51 \mathrm{~g}$ per bottle/sac.

\section{Element concentrations in substrates and their content in fruit bodies}

From among the 70 analysed elements, only 33 were determined in all the samples (Tables 2, 3, 4). Transport of elements present in substrate to mushroom fruiting bodies depends on many factors and concentration of their bioavailable forms is crucial for this process. Concentrations of $\mathrm{Eu}, \mathrm{Mn}, \mathrm{Pr}, \mathrm{Sn}(p<0.001), \mathrm{Ir}, \mathrm{Mg}, \mathrm{P}, \mathrm{Pb}, \mathrm{Zn}(p<0.01)$ and $\mathrm{Ba}(p<0.05)$ in substrate A were significantly higher than their levels in substrate B. On the other hand, concentrations of $\mathrm{Al}, \mathrm{B}, \mathrm{Hg}, \mathrm{Nd}, \mathrm{Ni}, \mathrm{Sr}(p<0.001)$ and $\mathrm{Li}, \mathrm{Ru}, \mathrm{Si}, \mathrm{Tl}$ $(p<0.01)$ in substrate $\mathrm{B}$ were significantly lower than those in substrate A. For the remaining elements $(\mathrm{Be}, \mathrm{Ca}, \mathrm{Cd}, \mathrm{Cr}$, $\mathrm{Cu}, \mathrm{Fe}, \mathrm{K}, \mathrm{La}, \mathrm{Na}, \mathrm{Pt}, \mathrm{Rb}, \mathrm{Sb}$, and Tm), no significant differences were observed in their concentrations in either of the substrates.

Generally, the highest content of the majority of the studied elements was recorded in $C$. maxima fruiting bodies
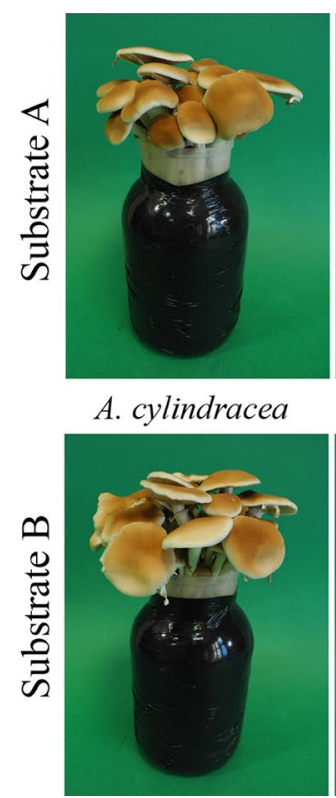

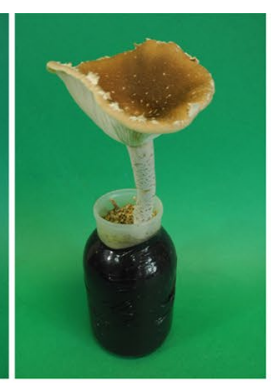

C. maxima

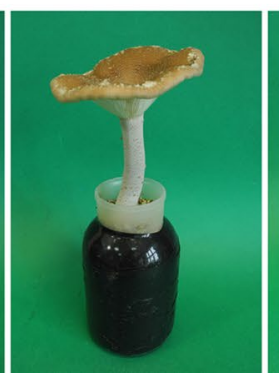

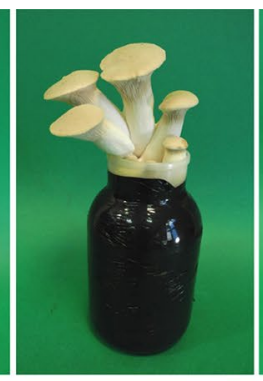

P. eryngii

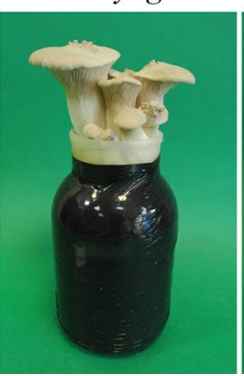

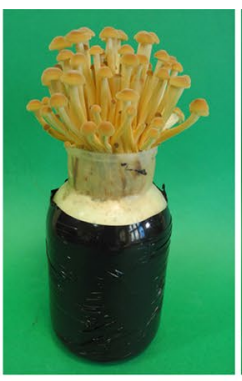

F. velutipes

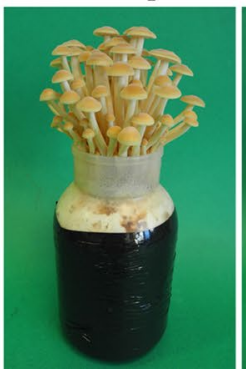

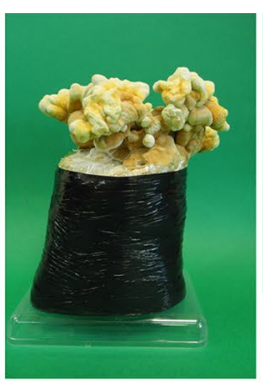

G. lucidum

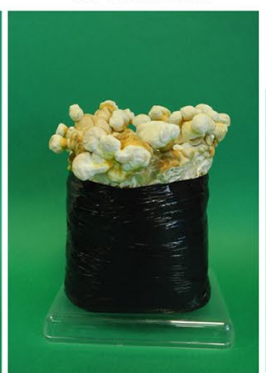

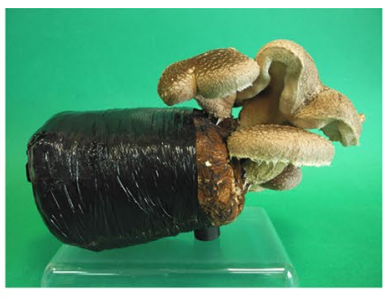

L. edodes

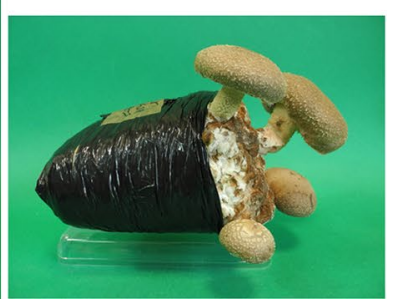

Fig. 1 Visual characteristics of morphology of the studied mushroom species 


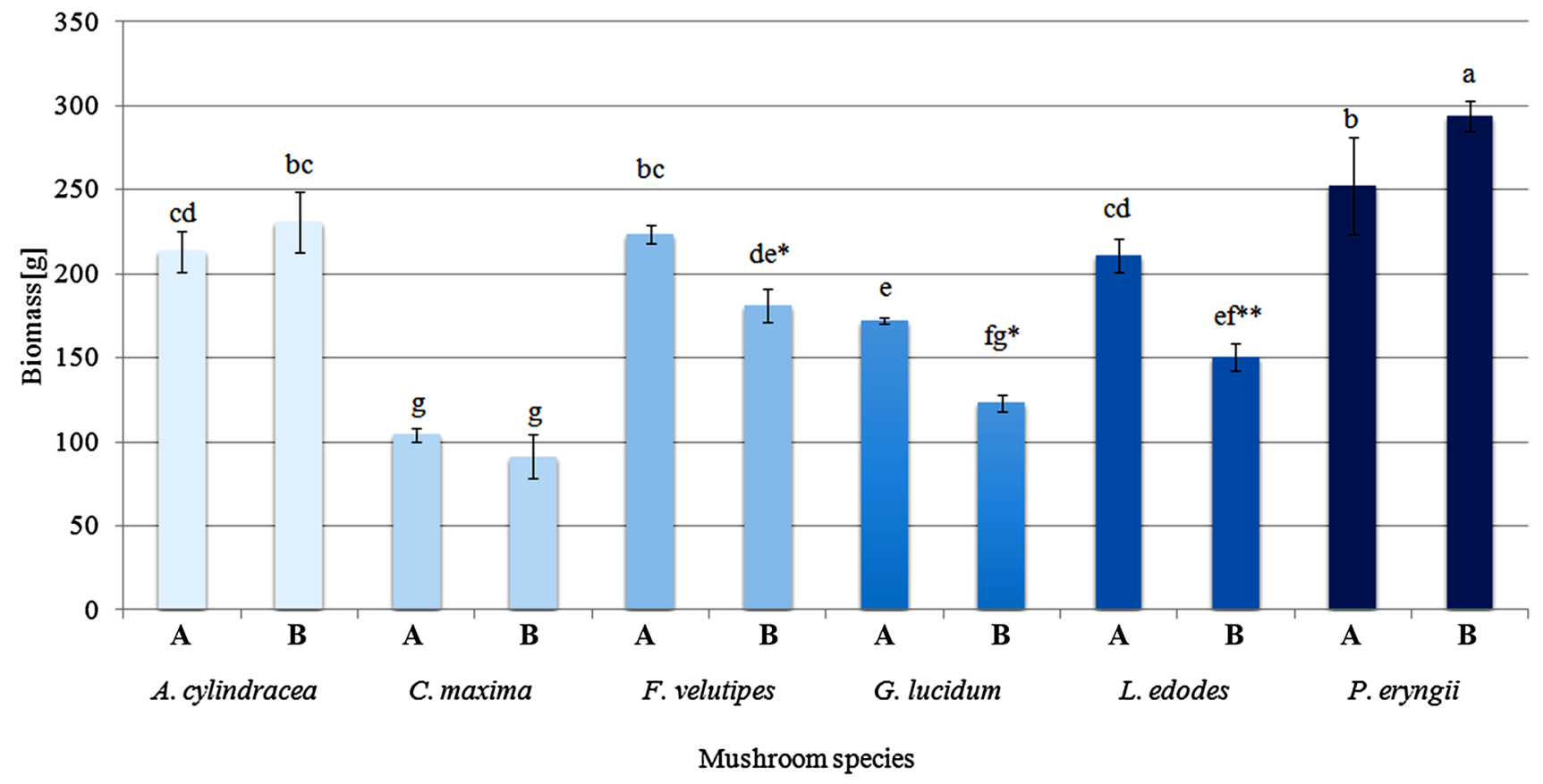

Fig. 2 Biomass crop [g] of mushroom species growing on substrates A and B

(Tables 2, 3, 4). This mushroom species growing on substrate A contained the highest level of $\mathrm{Ba}, \mathrm{Ca}, \mathrm{Cr}, \mathrm{La}, \mathrm{Li}$, $\mathrm{Mg}, \mathrm{Mn}, \mathrm{Na}, \mathrm{Nd}, \mathrm{Pr}, \mathrm{Si}, \mathrm{Sn}$ and $\mathrm{Sr}$, while growing on substrate B, the highest content of $\mathrm{Al}, \mathrm{B}, \mathrm{Ca}, \mathrm{Fe}, \mathrm{Hg}, \mathrm{La}, \mathrm{Li}, \mathrm{Ni}$, $\mathrm{Sn}, \mathrm{Sr}$ and $\mathrm{Tl}$.

A significantly higher concentration of particular elements in substrate was related to a generally (usually insignificantly) higher content of these metals in fruit bodies, e.g. for Al, Ba or Si. It is worth underlining that for selected elements, e.g. $\mathrm{Hg}, \mathrm{Mg}$ and $\mathrm{Mn}$, and mushroom species, significantly higher concentrations of these elements in substrate (substrate B for $\mathrm{Hg}$ and substrate A for $\mathrm{Mg}$ and $\mathrm{Mn}$ ) were associated with their lower accumulation in $F$. velutipes fruiting bodies growing on these most enriched substrates. Additionally, a significantly higher concentration of e.g. $\mathrm{Nd}$ in substrate $\mathrm{B}$ was related to a lower content of this metal in all studied mushroom species growing on this material. Many of these observations, e.g. for $C$. maxima were confirmed by values of the bioconcentration factor (BCF) presented in Table 5. The values of $\mathrm{BCF}$ are calculated as a ratio of the content of an element in fruiting bodies to the content in substrate (both in $\mathrm{mg} \mathrm{kg}^{-1} \mathrm{dm}$ ). Potassium was the most effectively accumulated mineral, especially by $A$. cylindrace $a$ and $L$. edodes growing on both the substrates, where the BCF was 7.3 and 7.6 for the former and 6.2 and 6.0 for the latter mushroom species, respectively, on substrates A and B.

To show the mutual relationship between the analysed elements and mushroom species, a principal component analysis (PCA) was performed. The relationships described above, especially the higher content of most of the elements in C. maxima growing on both the substrates were confirmed, particularly as shown in Fig. 3a, c (33 and 28 elements, respectively). For major minerals (Fig. 3b), such clear differences between $C$. maxima and the other mushroom species were not recorded, in spite of the fact that higher contents of $\mathrm{Ca}, \mathrm{Mg}$ and $\mathrm{P}$ were clearly visible. It is worth noting that for particular analyses, a considerable part of the variability, $58.65 \%(43.84+14.81) ; 81.50 \%$ $(56.01+25.49)$ and $58.04 \%(41.91+16.13)$ for 33,5 and 28 elements, respectively, was explained, which indicates that data in Fig. 3a-c present a reliable picture of the analysed relationships.

Only insignificant differences were found between the different mushroom species (growing on substrate A or substrate $\mathrm{B})$, where the Friedman chi-squared $\left(\chi_{\mathrm{F}}{ }^{2}\right)$ and $p$ values were as follows: $\chi_{\mathrm{F}}^{2}=0.1250, p=0.7237$ (A. cylindracea $), \chi_{\mathrm{F}}^{2}=1.4848, p=0.2230$ (C. maxima) $\cdot \chi_{\mathrm{F}}^{2}=0.0302$, $p=0.7918$ (F. velutipes), $\chi_{\mathrm{F}}^{2}=0.0303, p=0.8618$ (P. eryngii). On the other hand, significant differences $(p<0.05)$ for G. lucidum $\left(\chi_{\mathrm{F}}{ }^{2}=6.125, p=0.01333^{*}\right)$ and L. edodes $\left(\chi_{\mathrm{F}}^{2}=4.5, p=0.03389 *\right)$ were recorded.

According to the rank sum determined for all 33 elements jointly, F. velutipes, G. lucidum, L. edodes and $C$. maxima growing on substrate A were characterized by a higher content of the most of the studied elements compared to the same mushroom species growing on substrate B. The opposite situation was found for P. eryngii, while for 


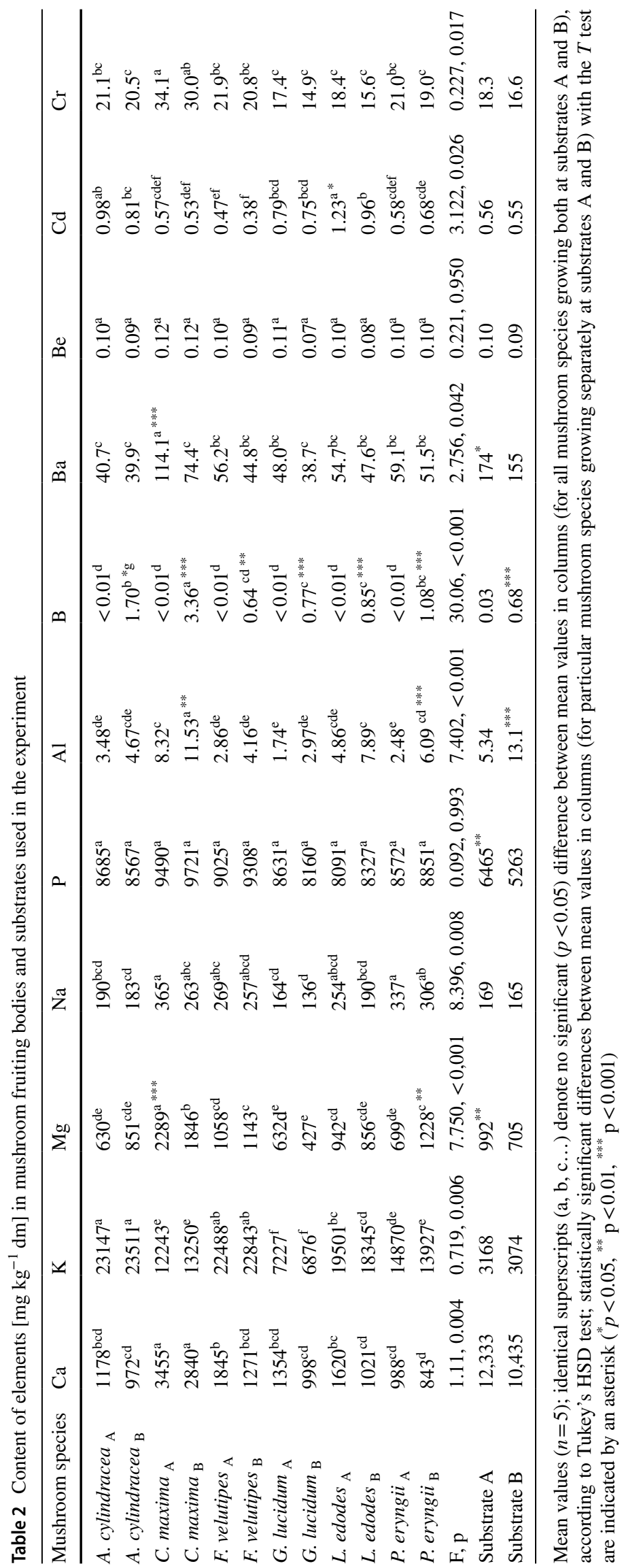




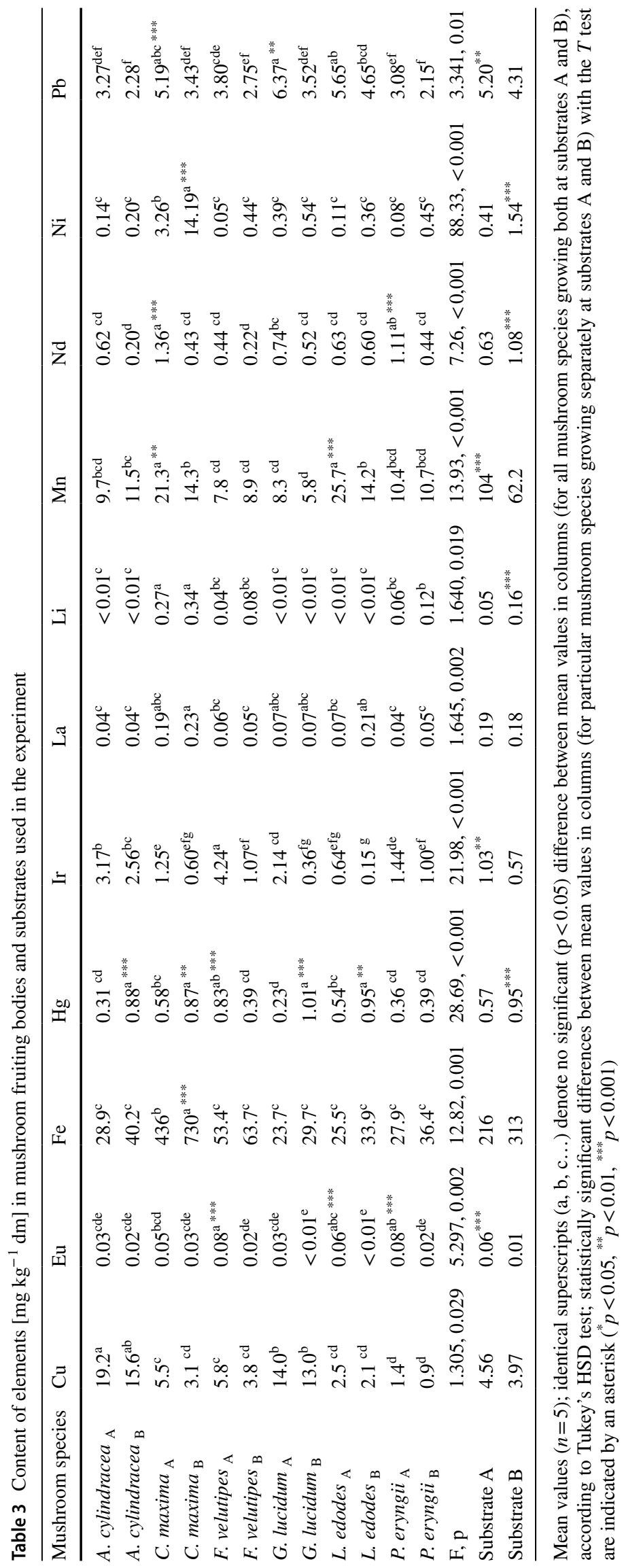




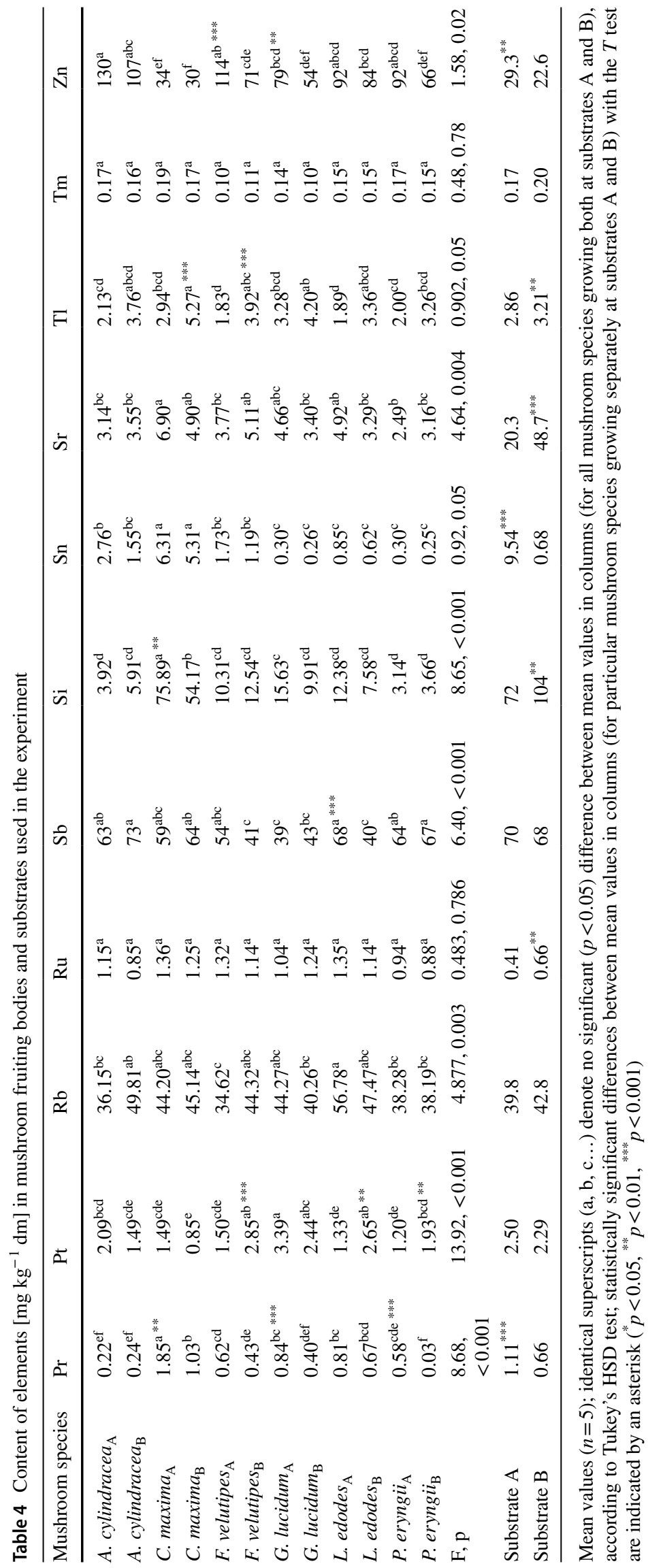


Table 5 Bioconcentration factor (BCF) values (only those $\geq 1$ ) for determined elements

\begin{tabular}{|c|c|c|c|c|c|c|c|c|c|c|c|c|c|c|}
\hline Mushroom species & $\mathrm{Al}$ & B & $\mathrm{Be}$ & $\mathrm{Cd}$ & $\mathrm{Cr}$ & $\mathrm{Cu}$ & $\mathrm{Eu}$ & $\mathrm{Fe}$ & $\mathrm{Hg}$ & K & $\mathrm{La}$ & $\mathrm{Li}$ & $\mathrm{Mg}$ & $\mathrm{Na}$ \\
\hline A. cylindracea $a_{\mathrm{A}}$ & & & 1.0 & 1.7 & 1.2 & 4.2 & & & 3.1 & 7.3 & & & & 1.1 \\
\hline A. cylindrace $a_{\mathrm{B}}$ & & 2.5 & 1.0 & 1.5 & 1.2 & 3.9 & & & 4.5 & 7.6 & & & 1.2 & 1.1 \\
\hline C. maxima $_{\mathrm{A}}$ & 3.1 & & 1.1 & 1.0 & 1.9 & 1.2 & & 2.0 & 1.0 & 3.9 & 1.0 & 5.4 & 2.3 & 2.2 \\
\hline C. maxima $_{\mathrm{B}}$ & 1.9 & 4.9 & 1.4 & 1.0 & 1.8 & & 2.8 & 2.3 & 1.1 & 4.3 & 1.3 & 2.1 & 2.6 & 1.6 \\
\hline F. velutipes $\mathrm{A}_{\mathrm{A}}$ & & & 1.0 & & 1.2 & 1.3 & 1.3 & & 1.4 & 7.1 & & & 1.1 & 1.6 \\
\hline F. velutipes v $_{\mathrm{B}}$ & & & 1.0 & & 1.3 & 1.0 & 2.0 & & 1.9 & 7.4 & & & 1.6 & 1.6 \\
\hline G. lucidum $_{\mathrm{A}}$ & & & 1.0 & 1.4 & & 3.1 & & & 2.1 & 2.3 & & & & 1.0 \\
\hline G. lucidum $_{\mathrm{B}}$ & & 1.1 & & 1.4 & & 3.3 & & & 1.1 & 2.2 & & & & \\
\hline L. edodes $\mathrm{A}$ & & & & 2.2 & 1.0 & & 1.0 & & & 6.2 & & & & 1.5 \\
\hline L. edodes $\mathrm{B}$ & & 1.3 & & 1.8 & & & & & 1.0 & 6.0 & 1.2 & & 1.2 & 1.2 \\
\hline P. eryngii ${ }_{\mathrm{A}}$ & & & 1.0 & 1.0 & 1.1 & & 1.4 & & 1.4 & 4.7 & & 1.1 & & 2.0 \\
\hline P. eryngii ${ }_{\mathrm{B}}$ & & 1.6 & 1.1 & 1.3 & 1.1 & & 2.1 & & 1.8 & 4.5 & & & 1.7 & 1.9 \\
\hline Mushroom species & $\mathrm{Nd}$ & $\mathrm{Ni}$ & $\mathrm{P}$ & $\mathrm{Pb}$ & $\operatorname{Pr}$ & $\mathrm{Pt}$ & $\mathrm{Rb}$ & $\mathrm{Ru}$ & $\mathrm{Sb}$ & $\mathrm{Si}$ & Sn & $\mathrm{Tl}$ & $\mathrm{Tm}$ & $\mathrm{Zn}$ \\
\hline A. cylindracea $a_{\mathrm{A}}$ & 1.0 & & 1.3 & & & & & 2.8 & & & & & 1.0 & 4.5 \\
\hline A. cylindrace $a_{\mathrm{B}}$ & & & 1.6 & & & & 1.2 & 1.3 & 1.1 & & 2.3 & 1.2 & & 4.7 \\
\hline C. maxima $_{\mathrm{A}}$ & 2.1 & 8.0 & 1.5 & 1.0 & 1.7 & & 1.1 & 3.3 & & 1.1 & & 1.0 & 1.1 & 1.2 \\
\hline C. maxima $_{\mathrm{B}}$ & & 9.2 & 1.8 & & 1.6 & & 1.1 & 1.9 & & 0.5 & 7.9 & 1.6 & & 1.3 \\
\hline F. velutipes v $_{\mathrm{A}}$ & & & 1.4 & & & & & & & & & & & 3.9 \\
\hline F. velutipes ${ }_{\mathrm{B}}$ & & & 1.8 & & & 1.2 & 1.0 & 1.7 & & & 1.8 & 1.2 & & 3.2 \\
\hline G. lucidum $_{\mathrm{A}}$ & 1.2 & 0.9 & 1.3 & 1.2 & & 1.4 & 1.1 & 2.5 & & & & 1.1 & & 2.7 \\
\hline G. lucidum ${ }_{\mathrm{B}}$ & & & 1.6 & & & 1.1 & & 1.9 & & & & 1.3 & & 2.4 \\
\hline L. edodes ${ }_{\mathrm{A}}$ & 1.0 & & 1.3 & 1.1 & & & 1.4 & 3.3 & 1.0 & & & & & 3.2 \\
\hline L. edodes $\mathrm{B}$ & & & 1.6 & 1.1 & 1.0 & 1.2 & 1.1 & 1.7 & & & & 1.0 & & 3.7 \\
\hline P. eryngii ${ }_{\mathrm{A}}$ & 1.7 & & 1.3 & & & & 1.0 & 2.3 & & & & & 1.0 & 3.1 \\
\hline P. eryngii ${ }_{\mathrm{B}}$ & & & 1.7 & & & & & 1.3 & 1.0 & & & 1.0 & & 2.9 \\
\hline
\end{tabular}

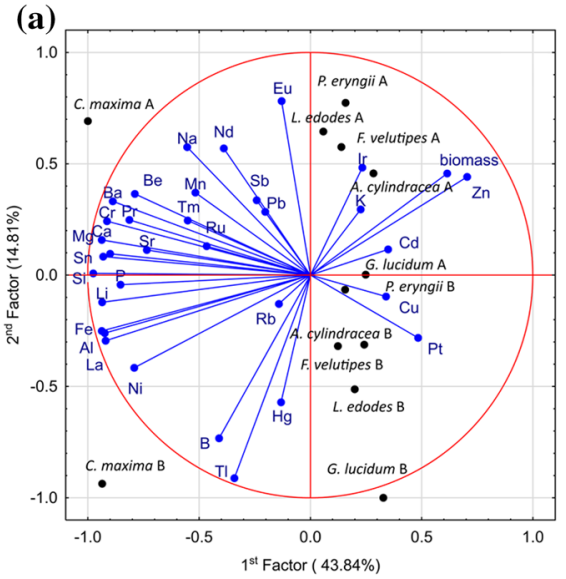

(b)

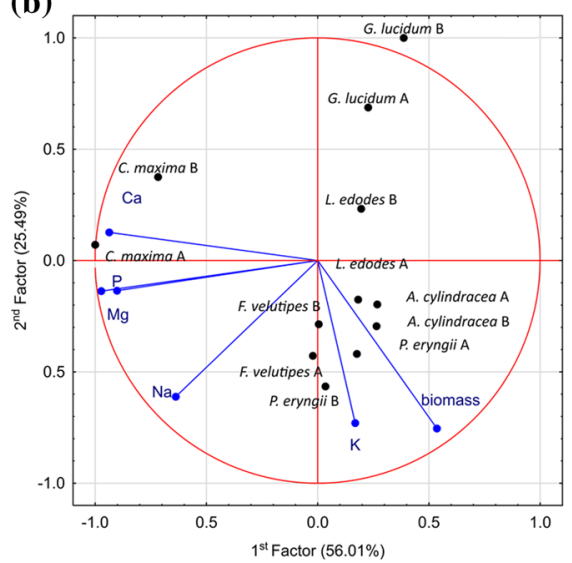

(c)

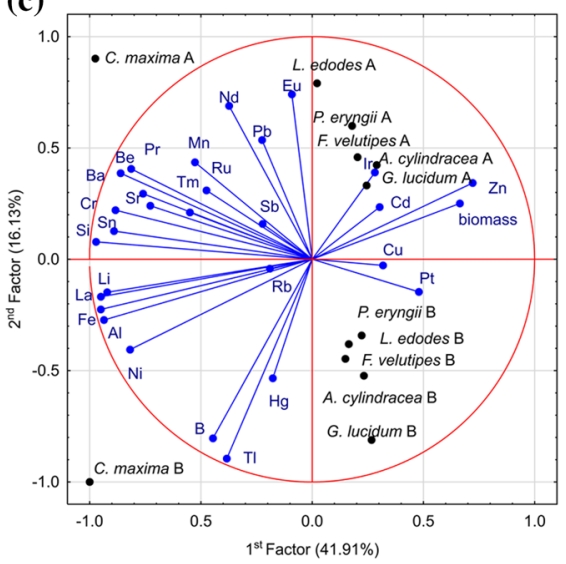

Fig. 3 Principal component analysis with regard to the coordinate factor variables (element contents and mushroom species growing on both substrates for a all 33 detectable elements, b macroelements, and c 28 elements)

(A) cylindracea the efficiency of accumulation of all studied elements jointly was almost the same, independently of the substrate used in this experiment. As regards major minerals, their total content in C. maxima, G. lucidum, L. edodes and $P$. eryngii fruiting bodies growing on substrate A was generally higher than in the same mushroom species growing on substrate B. An inverse situation was observed for $A$. cylindracea and $F$. velutipes. Interestingly, for the rest of the 
28 elements, the same relationships as for all 33 elements were recorded.

\section{Discussion}

It is imperative that mushrooms cultivated for human consumption contain no health risks associated with exposures to toxic elements. For this reason, numerous studies have already screened their content in a variety of edible mushrooms $[8,18,26,30]$. At the same time, production of fruiting bodies containing elevated contents of essential elements is also important. This study evaluated whether two substrates, ubiquitously used in the cultivation of various mushrooms, that differ in components and physicochemical properties, may yield different biomass of mushroom fruiting bodies, and whether the contents of chemical elements in the fruiting bodies may be different. The results of this study are important in view of maximizing the production efficiency of different mushroom species and ensuring the safety of such a process for consumers of the final food product.

Depending on the chemical composition and properties of the growing substrate, a yield of cultivated mushrooms and morphological features of their fruiting bodies may differ significantly, and result in unwanted macroscopic changes or yields below the cost-effectiveness threshold [7, 22]. The appearance of food products, including their colour, is usually an important feature for potential consumers and alterations may even decrease the value of the marketed product [31]. In these experiments, no macroscopic morphological differences were observed between mushrooms grown on the substrates A and B. However, the yields of $F$. velutipes, G. lucidum and L. edodes were significantly higher $(p<0.01)$ when grown using substrate A which was composed of alder and beech sawdust (1:1) supplemented with wheat bran, cornmeal, millet, chalk, gypsum, potassium dihydrogen orthophosphate, and magnesium sulphate. It is thus postulated to use this substrate preferentially over those composed of oak sawdust. In $A$. aegerita and $P$. eryngii a similar biomass of fruiting bodies was produced regardless of the employed substrate. The Pleurotus genus is already known to grow well on a variety of different substrates such as cereal straw, agricultural and forestry wastes, rice straw, wood chips mixed with sliced straw, blends of various sawdust with cotton husks, wheat bran, or soy $[8,32]$.

The content of chemical elements in fruiting bodies of the studied mushrooms was subject to great variation, depending both on mushroom species and employed substrate. Such variation was observed for both elements of nutritional value and (potentially) toxic metals. Calculation of bioconcentration factors revealed a tendency of some species to bioaccumulate significant levels of toxic metals (Table 5). As found, substrates tested in the present study were characterized by different levels of some toxic elements such as $\mathrm{Al}, \mathrm{Hg}, \mathrm{Ni}$ and $\mathrm{Pb}$, with higher values of the former three found for substrate B. These differences must arise from varying levels of toxic metals in particular ingredients used to compose studied substrates. As evidenced experimentally and observed in the field, the increase in content of various toxic elements in substrate or soil correlates with its increase in fruiting bodies of various mushroom species [28, 33-36]. All in all, this highlights a need to ensure that any commercial substrate used for their cultivation has to contain the lowest possible contents of these elements.

Aluminium was preferentially accumulated by $C$. maxima at levels similar to those found in commercial specimen of this species [29]. One should, however, note that other cultivated mushroom species, not included in this study, such as Laetiporus sulphureus or Grifola frondosa may contain its much higher content [37]. Nevertheless, in case of all six species studied in the present study, the highest $\mathrm{Al}$ content was observed when mushrooms were grown on substrate B that contained its significantly higher level. Although orally ingested $\mathrm{Al}$ has low bioavailability, its intake in the human population, currently estimated at a level of $11 \mathrm{~kg}$ per capita per year, is systematically rising indicating a need to monitor $\mathrm{Al}$ content in various foodstuffs and undertake actions to lower the exposures [38, 39].

In the case of $\mathrm{Cd}$, a BCF exceeding the value of 1 was found for A. cylindracea, C. maxima, G. lucidum, L. edodes and $P$. eryngii-regardless of the substrate used for cultivation. The greatest values were determined for $L$. edodes. One should note that $\mathrm{Cd}$ levels in both substrates were similar indicating that accumulation of this metal is species specific. Previous studies that screened the elemental content of $L$. edodes can be characterized by relatively high bioaccumulation of Cd compared with other cultivated mushrooms, at levels potentially adverse for human health [40-42]. These findings are worrisome if one considers that dietary $\mathrm{Cd}$ intake has been positively associated with cancer risk, and advocates Cd content in L. edodes sold as food to be frequently monitored.

As regards $\mathrm{Hg}, \mathrm{BCF}$ values higher than one were found for $F$. velutipes grown on substrate A and G. lucidum grown on substrate B. In general, $\mathrm{Hg}$ levels in cultivated mushrooms were lower than those often noted for wild-growing mushrooms although high site- and species-specific variations were noted for the latter [43-45]. However, $\mathrm{Hg}$ toxicity is highly dependent on its chemical forms (species), this element can induce a number of adverse effects on cardiovascular, pulmonary, urinary, gastrointestinal, neurological and reproductive levels, and over the years some strict limits have been enforced to decrease exposure to $\mathrm{Hg}$. Some mushroom species can grow well on substrates highly 
contaminated with $\mathrm{Hg}$ (e.g. A. bisporus, F. velutipes), accumulate it at levels largely exceeding allowance thresholds, with no changes in macronutrient composition [28, 46]. In turn, yield of other species such as G. lucidum can be significantly altered with increasing $\mathrm{Hg}$ content in overgrown substrate [47].

For $\mathrm{Pb}$, an increased $\mathrm{BCF}$ was determined only in $\mathrm{G}$. lucidum grown on substrate $\mathrm{A}$, and L. edodes grown on both the substrates. As shown previously, mushroom species from the Ganoderma and Pleurotus genera, available in trade, can contain higher $\mathrm{Pb}$ levels than those observed for various other cultivated mushroom species $[8,42]$. Considering that Ganoderma mushrooms are used to produce extracts or food supplements (due to their bitter taste they are not consumed after cooking), it is imperative to keep Pb levels low. In the case of food supplements, the maximum allowance level for $\mathrm{Pb}$ set by the European Commission is $3.0 \mathrm{mg} \mathrm{kg}^{-1}$ [48]. The limit would be exceeded if Ganoderma fruiting bodies grown on both the substrates A and B were to be used for the preparation of such formulas. One should also note that in case of all studied species, an increased content of $\mathrm{Pb}$ was noted when mushrooms were grown on substrate A which was characterized by higher level of this element. Various environmental studies indicate that mushrooms are characterized by low potential to bioaccumulate $\mathrm{Pb}$ and translocate it to fruiting bodies [26, 49-51]. However, one should note that uptake of elements in natural environment may be prone to more interfering factors compared to controlled cultivation process. However, some cultivated species as Agaricus bisporus are known to accumulate $\mathrm{Pb}$ poorly despite its high ambient content [52]; experimental cultivation of other species including Flammulina velutipes on substrates artificially contaminated with $\mathrm{Pb}$ led to significant uptake by its mycelia [53].

It has been previously observed that some cultivated mushrooms can contain significant levels of Ni [54], exceeding those often determined in wild-growing edible species [55]. In case of all six tested species, higher Ni content was observed when mushrooms were grown on substrate B that had increased Ni content. The positive correlation between ambient and mushroom content of $\mathrm{Ni}$ was previously evidenced by investigations in industrially polluted areas [56]. The present study found that $C$. maxima reveals a great affinity to uptake and accumulate Ni from a substrate, regardless of its composition. It is thus necessary to underline that cultivation of this species should ensure that employed substrates are low in Ni content. Food containing increased Ni levels is known to induce systemic contact dermatitis [57]. Importantly, a recent screening study of $C$. maxima available in trade found that it does not contain Ni levels of any concern to human health [42].

The studied mushrooms also varied in the contents of essential elements $(\mathrm{Ca}, \mathrm{Cr}, \mathrm{Cu}, \mathrm{Fe}, \mathrm{K}, \mathrm{Mg}, \mathrm{Mn}, \mathrm{Na}, \mathrm{P}$ and
$\mathrm{Zn})$. L. edodes contained the highest level of $\mathrm{Ca}$ and $\mathrm{Mn}$. The observed levels of these two elements were in line with previous studies investigating uptake of minerals by this mushroom species from sawdust substrate [58]. In turn, $C$. maxima has been characterized by the highest $\mathrm{Cr}$ and $\mathrm{P}$ contents, and distinctively high Fe levels. The latter observation was rather surprising as previously conducted comparative screening of marketed mushrooms originating from cultivations of found that this species has low $\mathrm{Fe}$ content although it the initial level of this element in overgrown substrates were unknown [37]. In the present study, higher Fe content was observed for mushrooms cultivated on Fe-richer substrate. It appears that if sufficient Fe levels in cultivation substrate $\left(200-300 \mathrm{mg} \mathrm{kg}^{-1} \mathrm{dm}\right.$ ) are ensured, $C$. maxima may represent a rich source of this mineral although its bioavailability would require further assessment. Cultivation of A. cylindracea on substrate $\mathrm{A}$ resulted in $\mathrm{Cu}$ and $\mathrm{Zn}$ levels higher than in the other studied mushroom species. The highest $\mathrm{K}$ content (exceeding $20 \mathrm{~g} \mathrm{~kg}^{-1} \mathrm{dm}$ ) was observed for A. cylindracea and $F$. velutipes. $P$. eryngii was the richest in $\mathrm{Na}$, regardless of the substrate used for cultivation. Considering the observed mean content of nutritional macro- and trace elements, it can be postulated to use preferentially substrate A for cultivation of C. maxima, G. lucidum and L. edodes, and substrate B for $A$. cylindracea and $F$. velutipes. In $P$. eryngii use of both the substrates resulted in comparable mineral composition. This is in line with previous observations made for other species from Pleurotus genus ( $P$. ostreatus and $P$. cystidiosus) grown on various substrates containing sawdust [12].

The difference in uptake and accumulation of chemical elements between the substrates A and B by the same mushroom species can be related to the difference in element content in the employed substrates. Moreover, substrates that are composed of different additives can vary in their physicochemical parameters such as $\mathrm{pH}$, redox potential (Eh) and salinity - all having a potentially great effect on element bioavailability $[59,60]$. Substrate A was more acidic $(\mathrm{pH}=6.45)$ compared to substrate $\mathrm{B}(\mathrm{pH}=6.99)$, and under such conditions higher availability of various elements can be expected. Both the substrates differed in Eh values (430 and $847 \mathrm{mV}$ for substrates A and B, respectively) and in salinity as indicated by electrical conductivity (1.04 and $2.87 \mathrm{dS} \mathrm{m}^{-1}$ for substrates A and B, respectively). Differences in the chemical characteristics of the substrates used in the cultivation of $F$. velutipes, $G$. lucidum and L. edodes having an effect on mineral composition in fruiting bodies and on mushroom growth and yielded biomass are similar to previous observations by Hoa et al. [12]. 


\section{Conclusion}

The present study proved that mineral composition in mushroom fruiting bodies is species specific and depends on the substrate used for cultivation. Cultivation of Clitocybe maxima, Ganoderma lucidum and Lentinula edodes is recommended on substrates composed of alder and beech sawdust, while cultivation of A. cylindracea and Flammulina velutipes yielded better results when oak sawdust substrate has been employed. The study confirms that $P$. eryngii can be cultivated on different media with comparable results. It further shows that $L$. edodes have a high affinity to accumulate $\mathrm{Cd}, C$. maxima can bioconcentrate $\mathrm{Al}$ and $\mathrm{Ni}$, Ganoderma lucidum $-\mathrm{Pb}$, while $F$. velutipes- $-\mathrm{Hg}$. These findings highlight a need to ensure that substrates used for cultivation of these mushroom species contain the lowest possible levels of these elements to protect the safety of consumers.

\section{Compliance with ethical standards}

Conflict of interest The authors declare that they have no competing interests.

Compliance with ethics requirements This article does not contain any studies with human or animal subjects.

Open Access This article is distributed under the terms of the Creative Commons Attribution 4.0 International License (http://creativeco mmons.org/licenses/by/4.0/), which permits unrestricted use, distribution, and reproduction in any medium, provided you give appropriate credit to the original author(s) and the source, provide a link to the Creative Commons license, and indicate if changes were made.

\section{References}

1. Cohen N, Cohen J, Asatiani MD, Varshney VK, Yu HT, Yang YC, Li YH, Mau JL, Wasser SP (2014) Chemical composition and nutritional and medicinal value of fruit bodies and submerged cultured mycelia of culinary-medicinal higher Basidiomycetes mushrooms. Int J Med Mushrooms 16:273-291

2. Prasad S, Rathore H, Sharma S, Yadav AS (2015) Medicinal mushrooms as a source of novel functional food. Int J Food Sci Nutr Diet 4:221-225

3. Valverde ME, Hernández-Pérez T, Paredes-López O (2015) Edible mushrooms: improving human health and promoting quality life. Int J Microbiol 2015:1-14

4. Kalač P (2016) Edible mushrooms: chemical composition and nutritional value. Elsevier, Amsterdam (ISBN 9780128044551)

5. Rzymski P, Klimaszyk P (2018) Is the yellow knight mushroom edible or not? A systematic review and critical viewpoints on the toxicity of Tricholoma equestre. Compr Rev Food Sci Food Saf. https://doi.org/10.1111/1541-4337.12374

6. Muszynska B, Kała K, Rojowski J, Grzywacz A, Opoka W (2017) Composition and biological properties of Agaricus bisporus fruiting bodies-a review. Pol J Food Nutr Sci 67:173-181

7. Rzymski P, Mleczek M, Niedzielski P, Siwulski M, Gąsecka M (2016) Cultivation of Agaricus bisporus enriched with selenium, zinc and copper. J Sci Food Agric 97:923-928
8. Siwulski M, Mleczek M, Rzymski P, Budka A, Jasińska A, Niedzielski P, Kalač P, Gąsecka M, Budzyńska S, Mikołajczak P (2017) Screening the multi-element content of Pleurotus mushroom species using inductively coupled plasma optical emission spectrometer (ICP-OES). Food Anal Method 10:487-496

9. FAOSTAT (2018) http://www.fao.org/faostat/en/\#data/QC. Accessed 21 Sept 2018

10. Agarwal S, Vaseem H, Kushwaha A, Gupta KK, Maurya S (2016) Yield, biological efficiency and nutritional value of Pleurotus sajor-caju cultivated on floral and agro-waste. Cell Mol Biol 62:1000130

11. Jeznabadi EK, Jafarpour M, Eghbalsaied S, Pessarakli M (2017) Effects of various substrates and supplements on king oyster (Pleurotus eryngii). Compost Sci Util 25:S1-S10

12. Hoa HT, Wang CL, Wang CH (2015) The effects of different substrates on the growth, yield, and nutritional composition of two oyster mushrooms (Pleurotus ostreatus and Pleurotus cystidiosus). Mycobiology 43:423-434

13. Owaid MN, Al-Saeedi SS, Sabaratnam V, Al-Assaffii IA, Raman J (2015) Growth performance and cultivation of four oyster mushroom species on sawdust and rice bran substrates. J Adv Biotechnol 4:423-429

14. Liang CH, Wu CY, Lu PL, Kuo YC, Liang ZC (2016) Biological efficiency and nutritional value of the culinary-medicinal mushroom Auricularia cultivated on a sawdust basal substrate supplemented with different proportions of grass plants. Saudi J Biol Sci. https://doi.org/10.1016/j.sjbs.2016.10.017 (2016)

15. Árvay J, Tomáš J, Hauptvogl M, Kopernická M, Kováčik A, Bajčan D, Massányi P (2014) Contamination of wild-grown edible mushrooms by heavy metals in a former mercury-mining area. $\mathrm{J}$ Environ Sci Health B 49:815-827

16. Niedzielski P, Mleczek M, Siwulski M, Gąsecka M, Kozak L, Rissmann I, Mikołajczak P (2014) Efficacy of supplementation of selected medicinal mushrooms with inorganic selenium salts. J Environ Sci Health B 49:929-937

17. Širić I, Humar M, Kasap A, Kos I, Mioč B, Pohleven F (2016) Heavy metal bioaccumulation by wild edible saprophytic and ectomycorrhizal mushrooms. Environ Sci Pollut Res 23:18239-18252

18. Rzymski P, Mleczek M, Siwulski M, Jasińska A, Budka A, Niedzielski P, Kalač P, Gąsecka M, Budzyńska S (2017) Multielemental analysis of fruit bodies of three cultivated commercial Agaricus species. J Food Compos Anal 59:170-178

19. Mleczek M, Siwulski M, Mikołajczak P, Gąsecka M, Rissmann I, Goliński P, Sobieralski K (2015) Differences in $\mathrm{Cu}$ content in selected mushroom species growing in the same unpolluted areas in Poland. J Environ Sci Health B 50:659-666

20. Poniedziałek B, Mleczek M, Niedzielski P, Siwulski M, Gąsecka M, Kozak L, Komosa A, Rzymski P (2017) Bio-enriched Pleurotus mushrooms for deficiency control and improved antioxidative protection of human platelets? Eur Food Res Technol 243:2187-2198

21. Mleczek M, Siwulski M, Rzymski P, Budzyńska S, Gąsecka M, Kalač P, Niedzielski P (2017) Cultivation of mushrooms for production of food biofortified with lithium. Eur Food Res Technol 243:1097-1104

22. Rzymski P, Mleczek M, Niedzielski P, Siwulski M, Gąsecka M (2016) Potential of cultivated Ganoderma lucidum mushrooms for the production of supplements enriched with essential elements. J Food Sci 81:C587-C592

23. Maseko T, Callahan DL, Dunshea FR, Doronila A, Kolev SD, $\mathrm{Ng} \mathrm{K}$ (2013) Chemical characterisation and speciation of organic selenium in cultivated selenium-enriched Agaricus bisporus. Food Chem 141:3681-3687

24. Rzymski P, Niedzielski P, Siwulski M, Mleczek M, Budzyńska S, Gąsecka M, Poniedziałek B (2017) Lithium biofortification of 
medicinal mushrooms Agrocybe cylindracea and Hericium erinaceus. J Food Sci Technol 54:2387-2393

25. Niedzielski P, Mleczek M, Magdziak Z, Siwulski M, Kozak L (2013) Selected arsenic species: As(III), As(V) and dimethylarsenic acid (DMAA) in Xerocomus badius fruiting bodies. Food Chem 141:3571-3577

26. Falandysz J, Borovička J (2013) Macro and trace mineral constituents and radionuclides in mushrooms: health benefits and risks. Appl Microbiol Biotechnol 97:477-501

27. Melgar MJ, Alonso J, García MA (2014) Total contents of arsenic and associated health risks in edible mushrooms, mushroom supplements and growth substrates from Galicia (NW Spain). Food Chem Toxicol 73:44-50

28. Rzymski P, Mleczek M, Siwulski M, Gąsecka M, Niedzielski P (2016) The risk of high mercury accumulation in edible mushrooms cultivated on contaminated substrates. J Food Compos Anal 51:55-60

29. Siwulski M, Rzymski P, Niedzielski P, Budka A, Gąsecka M, Kalač P, Jasińska A, Budzyńska S, Kozak L, Mleczek M (2017) Comparison of multielemental composition of Polish and Chinese mushrooms (Ganoderma spp.). Eur Food Res Technol 243:1555-1566

30. Nnorom IC, Jarzyńska G, Drewnowska M, Kojta AK, Pankavec S, Falandysz J (2013) Trace elements in sclerotium of Pleurotus tuber-regium (Ósu) mushroom-dietary intake and risk in Southeastern Nigeria. J Food Compos Anal 29:73-81

31. Nestel P, Bouis HE, Meenakshi JV, Pfeiffer W (2006) Biofortification of staple food crops. J Nutr 136:1064-1067

32. Akyüz M, Yildiz A (2008) Evaluation of cellulosic wastes for the cultivation of Pleurotus eryngii (DC. Ex Fr.) Quel. Afr J Biotechnol 7:1494-1499

33. Mleczek M, Niedzielski P, Siwulski M, Rzymski P, Gąsecka M, Goliński P, Kozak L (2015) Importance of low substrate as content in mushroom cultivation and safety of final food product. Eur Food Res Technol 242:355-362

34. Falandysz J, Bona H, Danisiewicz D (1994) Silver uptake by Agaricus bisporus from an artificially enriched substrate. Z Lebensm Unters Forsch 199:225-228

35. Falandysz J, Gucia M, Skwarzec B, Frankowska A, Klawikowska $\mathrm{K}$ (2002) Total mercury in mushrooms and underlying soil substrate from the Borecka Forest, Northeastern Poland. Arch Environ Contam Toxicol 42:145-154

36. Falandysz J, Treu R (2017) Fungi and environmental pollution. J Environ Sci Health Part B 52:147

37. Niedzielski P, Mleczek M, Budka A, Rzymski P, Siwulski M, Jasińska A, Gąsecka M, Budzyńska S (2017) A screening study of elemental composition in 12 marketable mushroom species accessible in Poland. Eur Food Res Technol 243:1759-1771

38. Exley C (2013) Human exposure to aluminium. Environ Sci Process Impacts 15:1807-1816

39. Rzymski P, Niedzielski P, Kaczmarek N, Jurczak T, Klimaszyk $P(2015)$ The multidisciplinary approach to safety and toxicity assessment of microalgae-based food supplements following clinical cases of poisoning. Harmful Algae 46:34-42

40. Mleczek M, Siwulski M, Rzymski P, Niedzielski P, Gąsecka M, Jasińska A, Budzyńska S, Budka A (2017) Multielemental analysis of Lentinula edodes mushrooms available in trade. J Environ Sci Health B 52:196-205

41. Mattila P, Könkö K, Eurola M, Pihlava JM, Astola J, Vahteristo L, Hietaniemi V, Kumpulainen J, Valtonen M, Piironen V (2001) Contents of vitamins, mineral elements, and some phenolic compounds in cultivated mushrooms. J Agric Food Chem $49: 2343-2348$
42. Huang Q, Jia Y, Wan Y, Li H, Jiang R (2015) Market survey and risk assessment for trace metals in edible fungi and the substrate role in accumulation of heavy metals. J Food Sci 80:1612-1618

43. Falandysz J, Gucia M, Mazur A (2007) Content and bioconcentration factors of mercury by Parasol Mushroom Macrolepiota procera. J Environ Sci Health A 42:735-740

44. Falandysz J (2017) Mercury accumulation of three Lactarius mushroom species. Food Chem 214:96-101

45. Saba M, Falandysz J, Nnorom IC (2016) Mercury bioaccumulation by Suillus bovinus mushroom and probable dietary intake with the mushroom meal. Environ Sci Pollut Res 23:14549-14559

46. Brunnert $\mathrm{H}$, Zadrazil $\mathrm{F}$ (1983) The translocation of mercury and cadmium into the fruit bodies of six higher fungi. A comparative study on species specificity in five lignocellulolytic fungi and the cultivated mushroom Agaricus bisporus. Eur J Appl Microbiol Biotechnol 17:358-366

47. Tham L, Matsuhashi S, Kume T (1999) Responses of Ganoderma lucidum to heavy metals. Mycoscience 40:209-213

48. Regulation (EC) (2008) No 629/2008: amending Regulation (EC) No 1881/2006. http://data.europa.eu/eli/reg/2008/629/oj. Accessed 21 Sept 2018

49. Jarzyńska G, Gucia M, Kojta AK, Rezulak K, Falandysz J (2011) Profile of trace elements in Parasol Mushroom (Macrolepiota procera) from Tucholskie Forest. J Environ Sci Health B 46:741-751

50. Malinowska E, Szefer P, Falandysz J (2004) Metals bioaccumulation by bay bolete Xerocomus badius from selected sites in Poland. Food Chem 84:405-416

51. Gąsecka M, Rzymski P, Mleczek M, Siwulski M, Budzyńska S, Magdziak Z, Niedzielski P, Sobieralski K (2017) The relationship between metal composition, phenolic acid and flavonoid content in Imleria badia from non-polluted and polluted areas. J Environ Sci Health B 52:171-177

52. Enke M, Roschig M, Matschiner H, Achtzehn MK (1979) Uptake of lead, cadmium and mercury by cultivated mushrooms. Nahrung 23:731-737

53. Zhu C, Li Z, Li D, Xin Y (2014) Pb tolerance and bioaccumulation by the mycelia of Flammulina velutipes in artificial enrichment medium. J Microbiol 52:8-12

54. Mleczek M, Rzymski P, Budka A, Siwulski M, Jasińska A, Kalač P, Poniedziałek B, Gąsecka M, Niedzielski P (2018) Elemental characteristics of mushroom species cultivated in China and Poland. J Food Comp Anal 66:168-178

55. Falandysz J, Chudzińska M, Barałkiewicz D, Drewnowska M, Hanć A (2017) Toxic elements and bio-metals in Cantharellus mushrooms from Poland and China. Environ Sci Pollut Res 24:11472

56. Barcan VS, Kovnatsky EF, Smetannikova MS (1998) Absorption of heavy metals in wild berries and edible mushrooms in an area affected by smelter emissions. Water Air Soil Pollut 103:173-195

57. Matiz C, Jacob SE (2011) Systemic contact dermatitis in children: how an avoidance diet can make a difference. Pediatr Dermatol 28:368-374

58. George PL, Ranatunga TD, Reddy SS, Sharma GC (2014) A comparative analysis of mineral elements in the mycelia and the fruiting bodies of Shiitake mushrooms. Am J Food Tech 9:360-369

59. Ayodele SM, Ojoghoro OJ (2007) Salt stress effects on the vegetative growth of Pleurotus tuberregium (FR) sing. J Biol Sci 7:1278-1281

60. Bellettini MB, Fiorda FA, Maieves HA, Teixeira GL, Ávila S, Hornung PS, Júnior AM, Hoffmann Ribani R (2016) Factors affecting mushroom Pleurotus spp. Saudi J Biol Sci. https://doi. org/10.1016/j.sjbs.2016.12.005 